\title{
Influence of Electrodeposition Parameters on Morphology and Polymer Inclusion into Polymer/Zn Composite Coatings
}

\author{
ALINA CRINA MURESAN*, LIDIA BENEA* \\ Interdisciplinary Research Centre in the Field of Eco-Nano Technology and Advanced Materials (CC-ITI), Faculty of \\ Engineering, Dunarea de Jos University of Galati, 47 Domneasca Str., 800008, Galati, Romania
}

\begin{abstract}
In this study different type of composite coatings was obtained by electrodeposition using zinc as matrix and polymeric particles as disperse phase in zinc sulphate electrolyte. The effects of some electrodeposition parameters on the thickness and morphology of obtained composite coatings were analysed by optical microscopy, Scanning Electron Microscopy (SEM) and Energy-Dispersive X-Ray Spectroscopy (EDX) methods. Polymeric particles inclusion into zinc matrix was correlated with imposed electrodeposition parameters. It was observed that the thickness of the coatings is influenced by electrodeposition parameters. From the morphology of the coatings, it could be concluded that pure zinc has a regular surface with hexagonal crystals, while the composite coatings have fine surface structure. Also, the electrodeposition parameters influence the inclusion of the dispersed phase into metallic matrix that will influence further the different properties of the composite materials.
\end{abstract}

Keywords: electrodeposition, phenol-formaldehyde resin, morphology, polymer particles inclusion

\section{Introduction}

Electrodeposition is a technique used to co-deposit a metallic matrix together with dispersed particles (ceramics, polymers, graphite) being the dispersion phase to obtain composite materials [1, 2]. Compared with other method to obtaining composite coatings (chemical vapour deposition, physical vapour deposition, laser melt injection etc.) the advantages of electrodeposition are low cost, low temperature conditions, uniformity of the obtained coatings and controlled deposition rate. The control of thickness and quality of the coatings are possible by controlling electrodeposition parameters [3-7]. The co-deposited particles can be polymers, ceramic particles, graphite and even metallic particles. The obtained composite coatings enhance properties such as hardness and wear and also improve the corrosion resistance. The composite coatings could also exhibit high thermal conductivity, electrical and photocatalytic properties. Some particles such as: silver [8], $\mathrm{B}_{4} \mathrm{C}$ [9], $\mathrm{CeO}_{2}$ [10], graphite [11], $\mathrm{TiO}_{2}$ [12], $\mathrm{V}_{2} \mathrm{O}_{5}$ [13], $\mathrm{SiC}$ [14] were used as dispersed phases for obtaining composite coatings in zinc matrix, but studies with polymeric particles used as dispersed phase are relatively limited. It was reported only few studies with composite materials obtained in zinc matrix with dispersed phase polymers such as polymethylmethacrylate (PMMA) [15], polystyrene (PS) [16], PEDOT (poly (3,4-ethylenedioxythiophene) [17], polytetrafluoroethylene (PTFE) [18], polyaniline (PANI) [19].

Electrodeposition parameters used for obtaining composite coatings are very important because, function of them, can be generated various morphologies and textures, which apart from the corrosion behaviour, can affect also some properties such as wear resistance, formability and paintability. Current density, electrodeposition time, bath composition, temperature, $p \mathrm{H}$, stirring rate, type and size of the particles used as dispersed phase are important parameters that controls the deposition process and will generate different morphologies of the composite layers and diverse content range of particles inclusion. All of these will influence the properties of composite coatings obtained by electrodeposition using zinc as metal matrix [20-24].

Zinc coatings can be obtained from cyanide galvanizing solutions or cyanide-free zinc solutions through electrodeposition process. The cyanide solutions are restricted because they have high toxicity; the regulations against water pollution and effluents disposal are very expensive [25]. Non-cyanide

\footnotetext{
*email:alina.muresan@ugal.ro, lidia.benea@ugal.ro
} 
solutions can be medium acid solutions (using sulphate or chloride anions) and alkali-zincate solutions [26]. Sulphate anions is used often because its relatively low cost, safety features and pollution control characteristics [27-29]. Utilization of additives in zinc electrodeposition was reported since 1907 and usually were used organic compounds. They improve the properties of the coatings (brightness, stress, grain size, smoothness) and enhance the operating performance (cathodic polarization, decreasing power consumption and increasing cathodic current efficiency). The most used additives are glue, gelatine, gum arabic, cetyltrimethylammonium bromide (CTAB), ethyl vanillin (EV), thiourea, dextrin, glycine and other organic additives, but they are environmental unfriendly because have lower thermal and chemical stability and high toxicity [30-34].

In the present work, we investigate the influence of some electrodeposition parameters such as current density, time of electrodeposition, content of phenol-formaldehyde resin used as dispersed phase in sulphate electrolyte bath on the thickness of composite layers, the morphology of composite coatings and polymer particles inclusion into zinc matrix. Phenol-formaldehyde resin (type novolac with commercial name RESITAL 6358/1 synthesized by Hüttenes - Albertus Group, Germany) used as dispersed phase is a thermo reactive polymer, that becomes plastic and insoluble by increasing temperature. Surfactants or additives were not used in the zinc sulphate electrolyte because they could react with resin particles and give wrong information about morphology, texture and inclusion of polymeric particles into zinc matrix.

\section{Materials and methods}

\subsection{Preparation of pure zinc and polymer/zinc composite coatings}

Pure zinc coatings were obtained on low-carbon steel substrate (DC04) from electrolyte solution with the following composition: $310 \mathrm{~g} / \mathrm{L} \mathrm{ZnSO}_{4} \times 7 \mathrm{H}_{2} \mathrm{O} ; 75 \mathrm{~g} / \mathrm{L} \mathrm{Na}_{2} \mathrm{SO}_{4} \times 10 \mathrm{H}_{2} \mathrm{O} ; 30 \mathrm{~g} / \mathrm{L} \mathrm{Al}_{2}\left(\mathrm{SO}_{4}\right)_{3} \times 18 \mathrm{H}_{2} \mathrm{O}$. Sulphate electrolyte was preferred because has higher cathodic potential than zinc chloride electrolyte. By adding sodium sulphate, it is increased the conductivity of electrolyte solution. Aluminium sulphate was used to stabilize the $p \mathrm{H}$ of the solution at a value of 3.8 and to obtain more shinning coatings. The electrodeposition was carried out at room temperature under the cathodic current density of $40 \mathrm{~mA} \cdot \mathrm{cm}^{-2}$ and $50 \mathrm{~mA} \cdot \mathrm{cm}^{-2}$ for $30 \mathrm{~min}$ and $60 \mathrm{~min}$. The stirring rate to keep a homogenous dispersion was optimised at $800 \mathrm{rpm}$. As anode material it was used the zinc metal plate with $99.99 \%$ purity and activated each time by immersing in $10 \% \mathrm{HCl}$ followed by distillate water wash. As cathode material (support for electrodeposited coatings) was used low-carbon steel plates (DC04).

To obtain the composite coatings in electrolytic bath was added $10 \mathrm{~g} / \mathrm{L}$ and $25 \mathrm{~g} / \mathrm{L}$ phenolformaldehyde resin particles with mean diameter size of $0.1-5.0 \mu \mathrm{m}$, maintaining the same parameters for electrodeposition used for obtaining of pure zinc coatings. Surfactants or additives were not used in the zinc sulphate electrolyte because they could react with resin particles and give wrong information about morphology and properties of new composite materials. The resin was molecular weight between $3392-3816 \mathrm{~g} / \mathrm{mol}$; melting point $70-80^{\circ} \mathrm{C}$; free phenol $<1 \%$; water content $<0.5 \%$. The phenol formaldehyde resin used as dispersed phase is not esterified.

There were obtained samples of pure zinc coatings and composite materials with different parameters for electrodeposition (current density, time for electrodeposition, content of dispersed phase into electrolytic bath), other parameters being constant. The samples obtained were submitted to experimental characterization. The symbols presented in Table 1 are used for tested samples.

Table 1. Symbols of samples used for testing

\begin{tabular}{|c|c|}
\hline Samples & Type of coatings and electrodeposition parameters \\
\hline $\mathrm{S} 1$ & $\begin{array}{c}\text { pure zinc coatings obtained at } 40 \mathrm{~mA} \cdot \mathrm{cm}^{-2}, \\
\text { time for electrodeposition } 60 \mathrm{~min}\end{array}$ \\
\hline $\mathrm{S} 2$ & $\begin{array}{c}\text { pure zinc coatings obtained at } 50 \mathrm{~mA} \cdot \mathrm{cm}^{-2}, \\
\text { time for electrodeposition } 30 \mathrm{~min}\end{array}$ \\
\hline $\mathrm{S} 3$ & $\begin{array}{c}\text { composite coatings obtained at } 40 \mathrm{~mA} \cdot \mathrm{cm}^{-2}, \text { time for electrodeposition } \\
60 \mathrm{~min}, 10 \mathrm{~g} / \mathrm{L} \text { phenol-formaldehyde resin into electrolyte solution }\end{array}$ \\
\hline
\end{tabular}




\begin{tabular}{|c|c|}
\hline S4 & $\begin{array}{r}\text { composite coatings obtained at } 50 \mathrm{~mA} \cdot \mathrm{cm}^{-2}, \text { time for electrodeposition } \\
30 \mathrm{~min}, 10 \mathrm{~g} / \mathrm{L} \text { phenol-formaldehyde resin into electrolyte solution }\end{array}$ \\
\hline S5 & $\begin{array}{r}\text { composite coatings obtained at } 40 \mathrm{~mA} \cdot \mathrm{cm}^{-2} \text {, time for electrodeposition } \\
60 \mathrm{~min}, 25 \mathrm{~g} / \mathrm{L} \text { phenol-formaldehyde resin into electrolyte solution }\end{array}$ \\
\hline S6 & $\begin{array}{c}\text { composite coatings obtained at } 50 \mathrm{~mA} \cdot \mathrm{cm}^{-2}, \text { time for electrodeposition } \\
30 \mathrm{~min}, 25 \mathrm{~g} / \mathrm{L} \text { phenol-formaldehyde resin into electrolyte solution }\end{array}$ \\
\hline
\end{tabular}

\subsection{Characterization of the coatings}

\subsubsection{Thickness of the coatings}

The thicknesses of pure zinc and polymer/zinc composite coatings were evaluated in cross sections of the samples by optical microscopy using a Reichert-Jung optic microscope.

\subsubsection{Morphology of the coatings and polymer particles inclusion}

The morphology of the coating surfaces and polymeric particles inclusion into zinc matrix were evaluated by scanning electron microscopy and energy-dispersive X-ray spectroscopy using a scanning electron microscope type JEOL JSM-T220A. The polymeric particles inclusion into zinc matrix was evaluated on the composite coatings surface using EDX chemical analyses. The phenol-formaldehyde resin contains hydrogen, oxygen and carbon. The presence of hydrogen cannot be determined because it has a very small atomic weight, oxygen could be provided from polymer and from zinc oxide on the surfaces. So that the average content of unit molecular weight of polymer from hybrid coatings was calculated using the average content of carbon.

\section{Results and discussions}

\subsection{Thickness of the coatings}

The thickness of pure zinc and polymer/zinc composite coatings are presented in Figures 1 and 2.

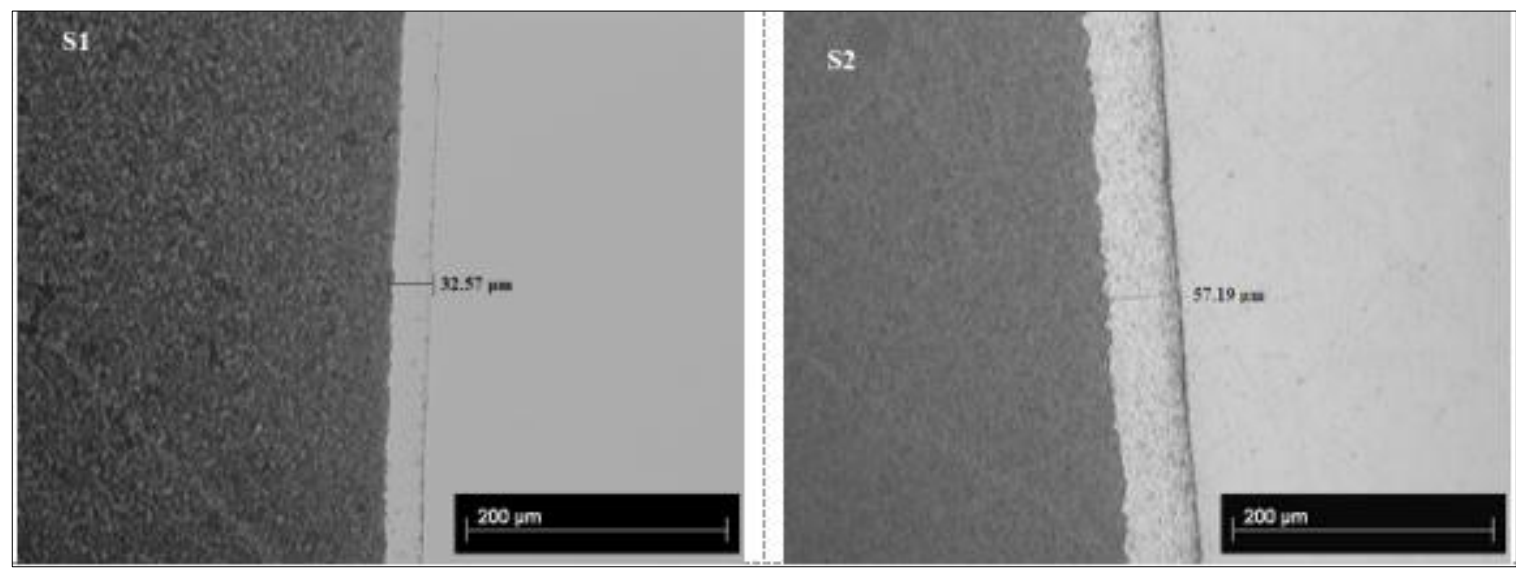

Figure 1. The cross - sectional images obtained with the optical microscope show the thickness of the pure zinc coatings (X 500)

From Figure 1 it could be observed that the thickness of zinc coatings obtained at current density of $50 \mathrm{~mA} \cdot \mathrm{cm}^{-2}$ during $30 \mathrm{~min}(57.19 \mu \mathrm{m})$ are higher than the thickness obtained at $40 \mathrm{~mA} \cdot \mathrm{cm}^{-2}$ during $60 \mathrm{~min}$ of electrodeposition $(32.57 \mu \mathrm{m})$.

The thickness of polymer/zinc composite coatings has values between $25.89 \mu \mathrm{m}$ (S3) and $60.35 \mu \mathrm{m}$ (S5). It could be observed that by increasing the polymeric particles content into electrolyte solution from $10 \mathrm{~g} / \mathrm{L}$ to $25 \mathrm{~g} / \mathrm{L}$ at $40 \mathrm{~mA} \cdot \mathrm{cm}^{-2}$ the thickness of the coatings is increasing from $25.89 \mu \mathrm{m}$ to 60.35 $\mu \mathrm{m}$, but at $50 \mathrm{~mA} \cdot \mathrm{cm}^{-2}$ the thickness of the coatings is decreasing from $58.21 \mu \mathrm{m}$ to $47.73 \mu \mathrm{m}$. This decrease of thickness of the composite coatings at same current density, same electrodeposition time and increase the content of the polymer particles in electrolyte solution could be explained by the grain refinement of coatings in the presence of polymeric particles and polymeric filling of the space between zinc crystals 

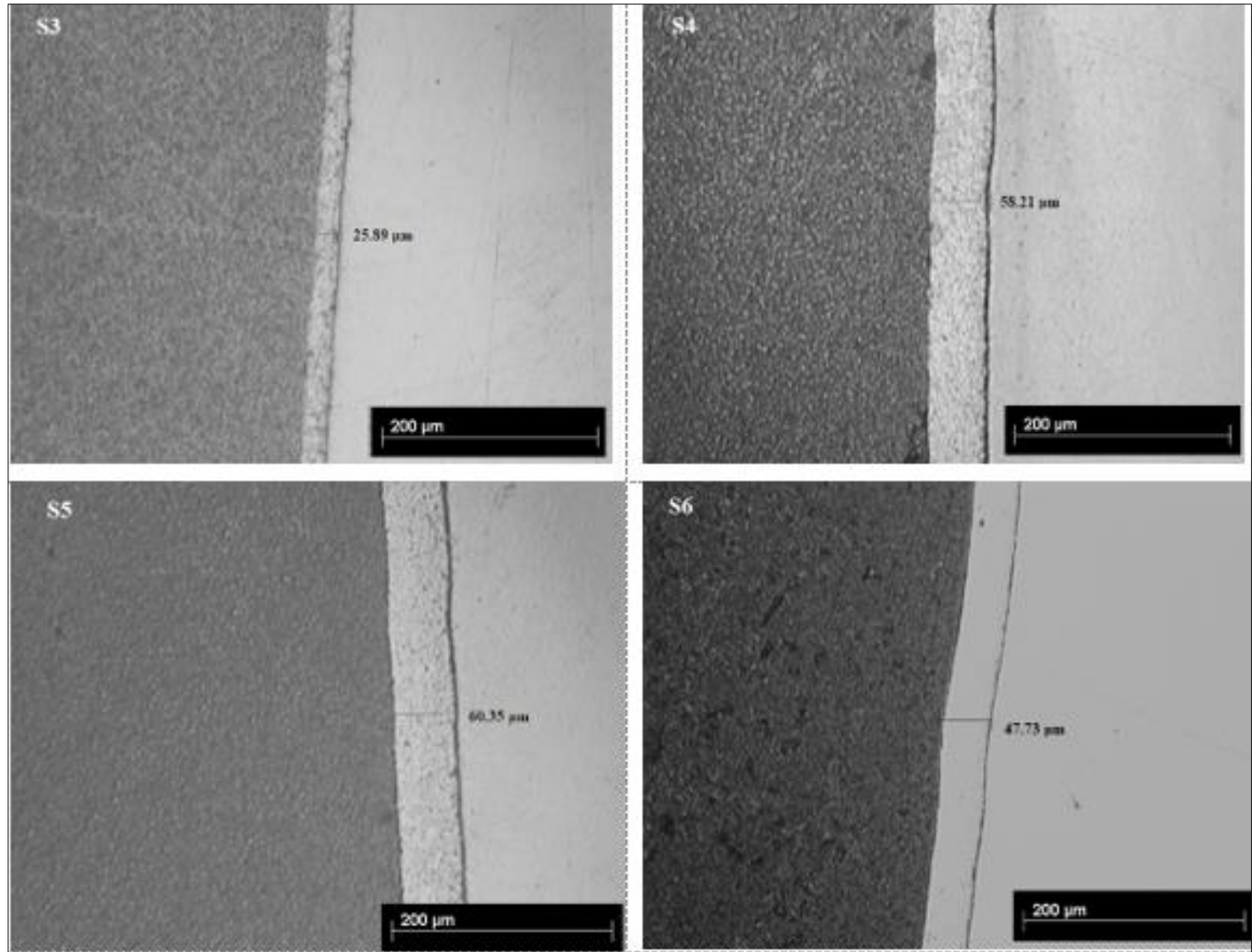

Figure 2. The cross - sectional images obtained with the optical microscope show the thickness of the composite coatings (X 500)

\subsubsection{Morphology of the coatings and polymer particles inclusion}

Figures 3 - 5 shows the morphological aspects of pure zinc and polymer/zinc composite coatings using scanning electron microscopy.
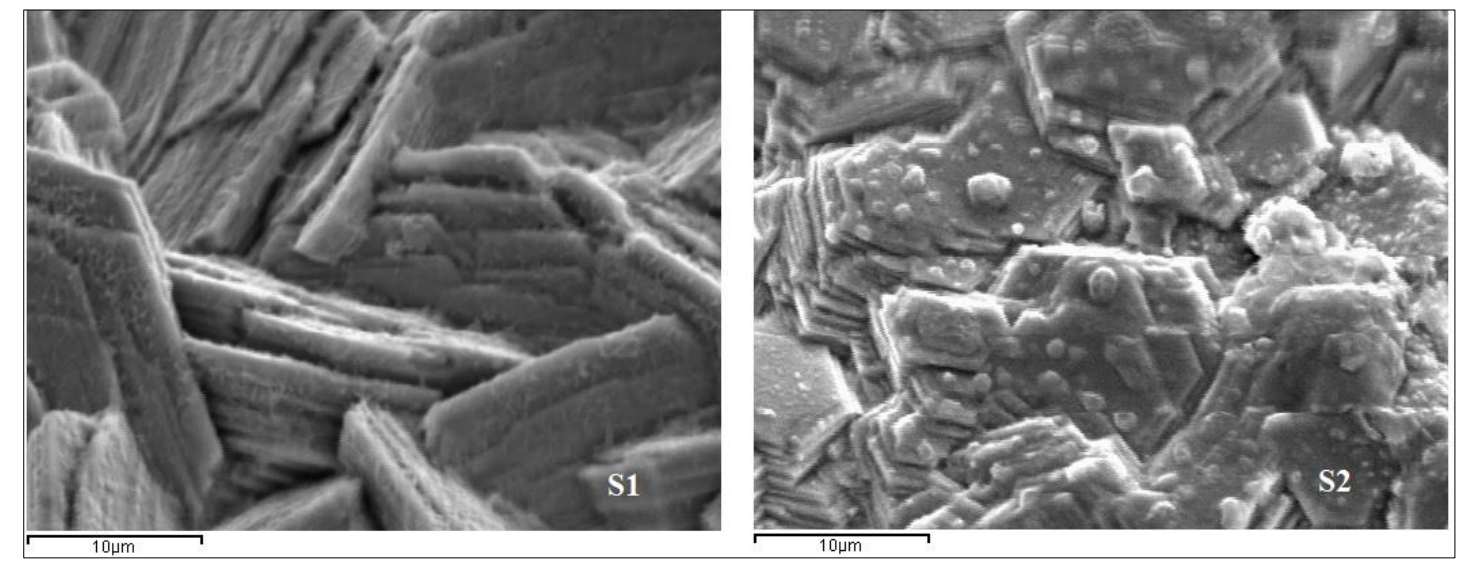

Figure 3. SEM surface morphology of pure zinc coatings (x 3500)

From scanning electron microscopy micrographs of the pure zinc coatings, it could be observed that the electrodeposits appear sufficiently well distributed, compact and continuous. SEM image for S1 sample is in the form of irregular arrangement of compact, thin hexagonal crystals having certain degree of orientation perpendicular to the substrate surface. The SEM image of S2 sample shows random distribution of laminated thin hexagonal platelets. From SEM image of S2 sample it could be observed 
spheroid forms with different diameter that probably are provided from the hydrogen bubbles that could appear with increasing of the current density. At higher current density the rate of deposition and coatings build-up are faster and at smaller current density the rate of nucleation sites is lower, the zinc platelets are bigger in order to cover the whole surface of the substrate.

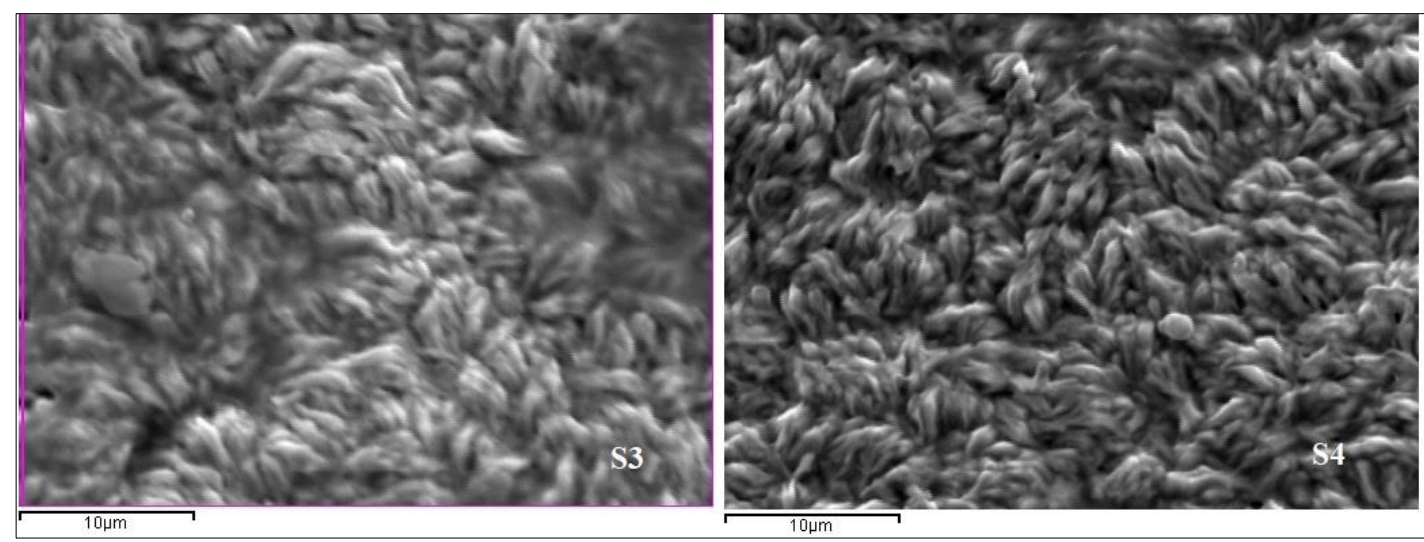

Figure 4. SEM surface morphology of polymer/zinc composite coatings obtained with $10 \mathrm{~g} / \mathrm{L}$ of polymer particles into electrolyte solution (x 3500)
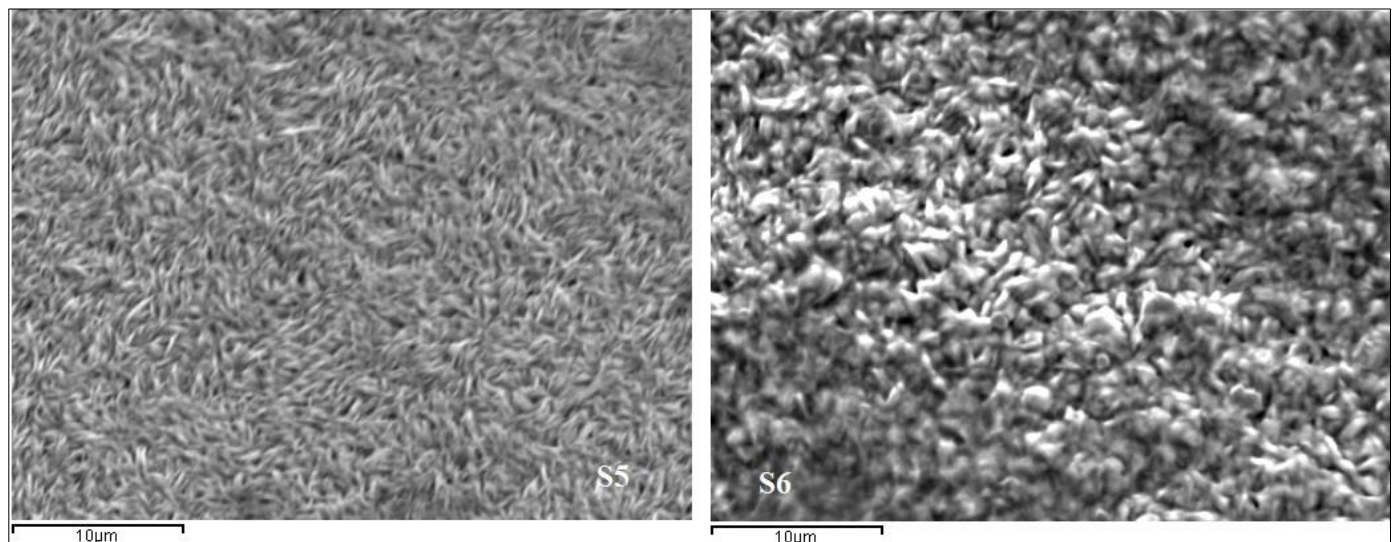

Figure 5. SEM surface morphology of polymer/zinc composite coatings obtained with $25 \mathrm{~g} / \mathrm{L}$ of polymer particles into electrolyte solution (x 3500)

From the SEM images of composite materials (Figures 4 and 5) it could be observed that in the presence of polymeric particles appears grain refinement of the surfaces, because the polymeric particles included into zinc matrix have a catalytic effect to increase the zinc nucleation sites and inhibition effect on metal crystals growth. In the presence of phenol-formaldehyde resin particles the zinc crystals become finely crystalline because the polymeric particles disorder the hexagonal crystals of zinc.

The inclusion of polymeric particles into metallic zinc matrix influences the growth of zinc crystals such that it brought about a reduction in the crystallite size. The phenol-formaldehyde resin particles included into the deposited coatings increase the rate of nucleation and inhibited the growth of zinc crystals resulting finally a more fine-grained composite deposit.

Figures 6 and 7 presents the X-ray mapping of zinc, carbon and oxygen for samples S4 and S6 in order to evaluate the uniformity of the polymeric particles inclusion into metallic matrix. From the spatial distribution of elements (zinc, carbon and oxygen) resulted from composite materials it was observed that the coatings obtained are uniform having even an uniform element distribution on the surface. 


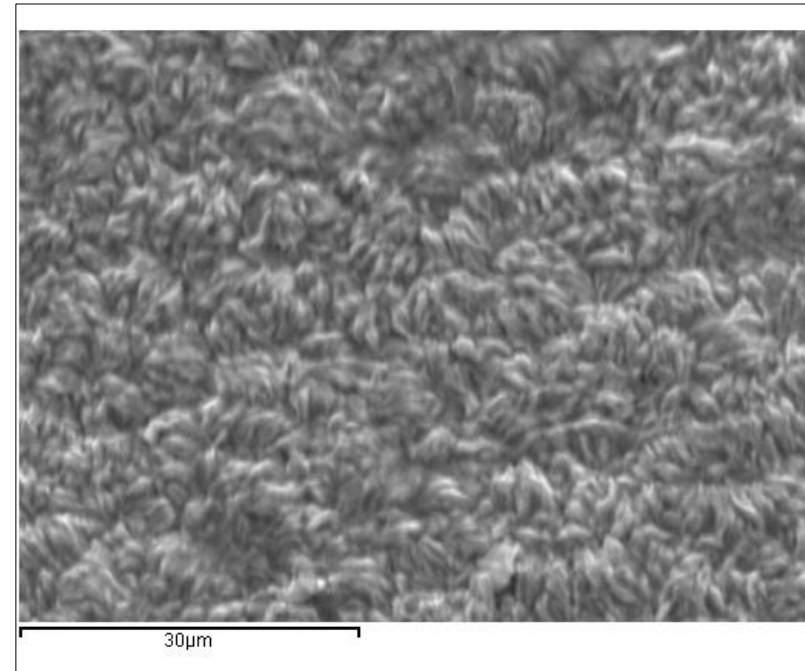

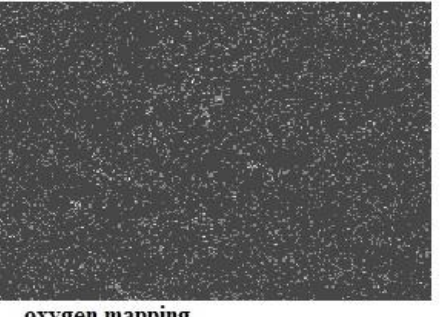

oxygen mapping

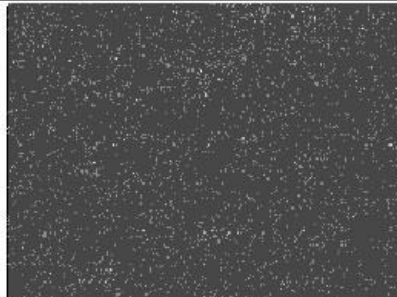

carbon mapping

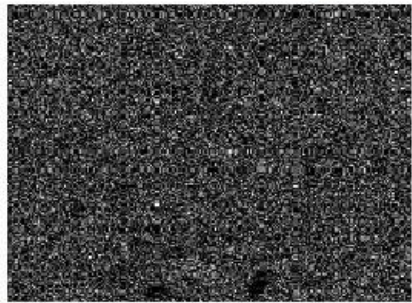

zinc mapping

Figure 6. SEM-EDX mapping of zinc, carbon and oxygen for sample S4 (x 2000)

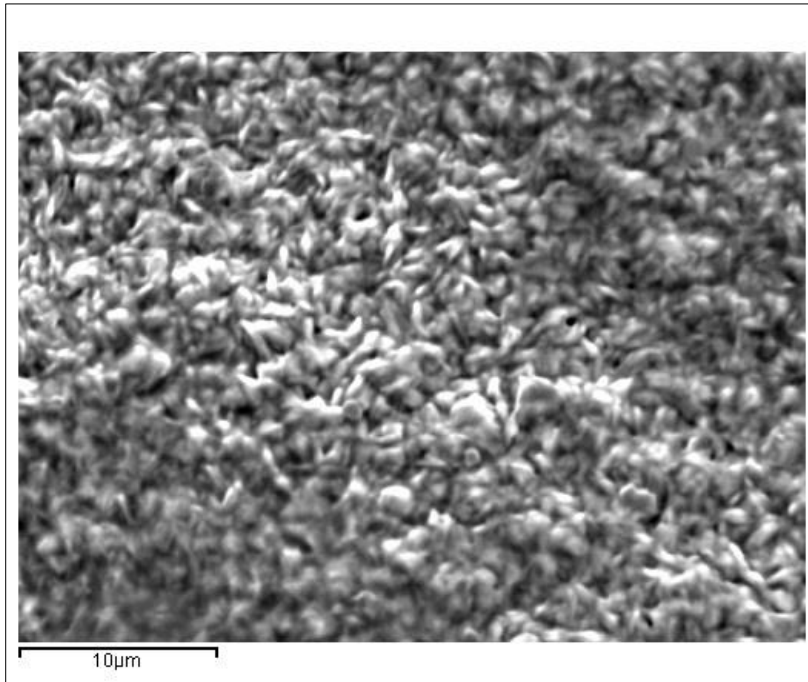

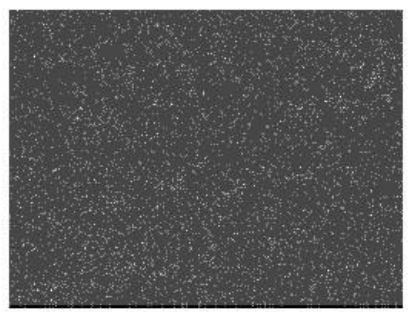

oxygen mapping

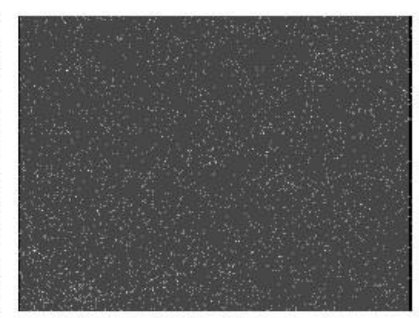

carbon mapping

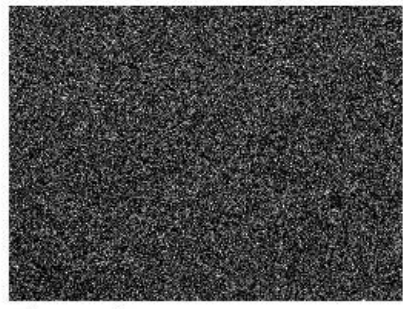

zinc mapping

Figure 7. SEM-EDX mapping of zinc, carbon and oxygen for sample S6 (x 3500)

In order to evaluate the inclusion of polymeric particles into zinc matrix it was used EDX chemical analyses. The polymer used as dispersed phase to obtain composite materials contains hydrogen, oxygen and carbon. The average content of molecular mass unit of polymer from composite coatings was calculated using the average content of carbon, because the hydrogen has a very small atomic weight and cannot be determinate and oxygen could be provided from polymer and from zinc oxide on the surfaces. The average elemental (carbon, oxygen and zinc) composition of the coating samples and the inclusion of polymeric particles into zinc matrix calculated from carbon average content is given in the Table 2.

Table 2. The average elemental composition of S1 - S6 samples from SEM-EDX analysis and inclusion of polymeric particles calculated from EDX data

\begin{tabular}{|c|c|c|c|}
\hline Sample & Element & Mean values of wt. \% & $\begin{array}{c}\text { Inclusion of polymer particles } \\
\text { wt.\% }\end{array}$ \\
\hline S1 & $\mathrm{Zn}$ & 100.00 & 0.00 \\
\hline S2 & $\mathrm{Zn}$ & 100.00 & 0.00 \\
\hline \multirow{3}{*}{ S3 } & $\mathrm{C}$ & 38.26 & \multirow{2}{*}{48.28} \\
\cline { 2 - 3 } & $\mathrm{O}$ & 6.60 & \\
\cline { 2 - 3 } & $\mathrm{Zn}$ & 55.14 & \\
\hline S4 & $\mathrm{C}$ & 30.50 & \\
\hline
\end{tabular}




\begin{tabular}{|c|c|c|c|}
\hline \multirow{4}{*}{ S5 } & O & 5.45 & \multirow{2}{*}{38.48} \\
\cline { 2 - 3 } & $\mathrm{Zn}$ & 64.05 & \\
\cline { 2 - 3 } & $\mathrm{C}$ & 14.39 & \multirow{2}{*}{18.16} \\
\cline { 2 - 3 } & $\mathrm{O}$ & 4.50 & \\
\hline \multirow{3}{*}{ S6 } & $\mathrm{Zn}$ & 81.11 & \multirow{2}{*}{36.68} \\
\cline { 2 - 3 } & $\mathrm{C}$ & 29.07 & \\
\cline { 2 - 3 } & $\mathrm{O}$ & 5.60 & \\
& $\mathrm{Zn}$ & 65.33 & \\
\hline
\end{tabular}

From the values presented in the Table 2, the inclusion of polymeric particles into zinc matrix is ranged between $18.16 \%$ wt. and $48.28 \%$ wt. For samples obtained with $10 \mathrm{~g} / \mathrm{L}$ polymeric particles into electrolyte solution, the increase the current density from $40 \mathrm{~mA} \cdot \mathrm{cm}^{-2}$ to $50 \mathrm{~mA} \cdot \mathrm{cm}^{-2}$ and the decrease the time of electrodeposition from $60 \mathrm{~min}$ to $30 \mathrm{~min}$ results in a decrease of particles inclusion from $48.28 \%$ wt. to $38.48 \%$ wt. A higher decrease of polymeric particles inclusion is obtained at current density of $40 \mathrm{~mA} \cdot \mathrm{cm}^{-2}$, time for electrodeposition $60 \mathrm{~min}$ and $25 \mathrm{~g} / \mathrm{L}$ polymeric particles into electrolyte solution. It could be concluded that by increasing the content of polymeric particles into electrolyte solution from $10 \mathrm{~g} / \mathrm{L}$ to $25 \mathrm{~g} / \mathrm{L}$ at a value of current density of $40 \mathrm{~mA} \cdot \mathrm{cm}^{-2}$, the inclusion of dispersed phase into metallic matrix was decreased about three times (from $48.28 \%$ wt. to $18.16 \%$ wt.). At 50 $\mathrm{mA} \cdot \mathrm{cm}^{-2}$ the increase of polymeric particles into electrolyte solution results in a small variation of polymeric particles inclusion into zinc matrix (from $38.48 \%$ wt. to $36.68 \%$ wt.).

\section{Conclusions}

Composite materials coatings were successfully electrodeposited using phenol-formaldehyde resin as dispersed phase and zinc as metallic matrix. For electrodeposition the surfactants or additives were not used.

Polymeric particles used as dispersed phase affect the electrodeposition process by modifying the coating thickness and the morphology of composite coatings obtained as compared with pure zinc coatings obtained at same electrodeposition parameters.

The pure zinc coatings obtained appear sufficiently well compact and continuous, while the composite material coatings obtained with polymeric particles appear with a grain refinement of the surface, because the polymeric particles included into zinc matrix have a catalytic effect in increasing of zinc nucleation sites and inhibition effect of metallic crystal growth. The phenol-formaldehyde resin particles are uniformly included into composite deposit by increasing the rate of nucleation and inhibition of the zinc crystals growth resulting finally a fine-grained composite deposit.

The electrodeposition parameters for obtaining composite material coatings influence the inclusion of polymeric particles into metallic matrix, which will affect further the properties of composite material coatings.

\section{References}

1.WALSH, F.C., WANG, S., ZHOU, N., The electrodeposition of composite coatings: Diversity, applications and challenges, Curr. Opin. Electrochem., 20, 2020, 8-19.

https://doi.org/10.1016/j.coelec.2020.01.011

2.WALSH, F.C., LEON, C.P., A review of the electrodeposition of metal matrix composite coatings by inclusion of particles in a metal layer: an established and diversifying technology, Trans. IMF., 92, 2014, 83-98. https://doi.org/10.1179/0020296713Z.000000000161

3.BESHORE, A.C., FLORI, B.J., SCHADE, G., O'KEEFE, T.J., Nucleation and growth of zinc electrodeposited from acidic zinc solutions, Appl. Electrochem., 17 (4), 1988, 765-772.

https://doi.org/10.1007/BF01007813

4.SAIDI, R., ASHRAFIZADEH, F., RAEISSI, K., KHARAZIHA, M., Electrochemical aspects of zinc oxide electrodeposition on $\mathrm{Ti}_{6} \mathrm{~A}_{14} \mathrm{~V}$ alloy, Surf. Coat. Technol., 402, 2020, 126297.

https://doi.org/10.1016/j.surfcoat.2020.126297 
5.RAGHAVENDRAA, C.R., BASAVARAJAPPAB, S., SOGALADC, I., SAUNSHI, V.K.K., Study on surface roughness parameters of nano composite coatings prepared by electrodeposition process, Mater. Today, 38 (5), 2021, 3110-3115. https://doi.org/10.1016/j.matpr.2020.09.493

6.JAIN, R., PITCHUMANI, R., Fabrication and characterization of zinc-based superhydrophobic coatings, Surf. Coat. Technol., 337, 2018, 223-231. https://doi.org/10.1016/j.surfcoat.2018.01.014 7.OHBA, M., SCARAZZATO, T., ESPINOSA, D.C.R., PANOSSIAN Z., Study of metal electrodeposition by means of simulated and experimental polarization curves: Zinc deposition on steel electrodes, Electrochim. Acta, 309, 2019, 86-103. https://doi.org/10.1016/j.electacta.2019.04.074

8.REYES-VIDAL, Y., SUAREZ-ROJAS, R., RUIZ, C., TORRES, J., ŢĂLU, Ş., MÉNDEZ, A., TREJO, G., Electrodeposition, characterization, and antibacterial activity of zinc/silver particle composite coatings, Appl. Surf. Sci., 342, 2015, 34-41. https://doi.org/10.1016/j.apsusc.2015.03.037

9.PRAVEEN KUMAR, C.M., VENKATESHA, T.V., CHANDRAPPA, K.G., Effect of surfactants on co-deposition of $\mathrm{B}_{4} \mathrm{C}$ nanoparticles in $\mathrm{Zn}$ matrix by electrodeposition and its corrosion behavior, Surf. Coat. Technol., 206, 2012, 2249-2257. https://doi.org/10.1016/j.surfcoat.2011.09.075

10. NEMES, P.I., LEKKA, M., FEDRIZZI, L., MURESAN, L.M., Influence of the electrodeposition current regime on the corrosion resistance of $\mathrm{Zn}-\mathrm{CeO}_{2}$ nanocomposite coatings, Surf. Coat. Technol., 252, 2014, 102-107. https://doi.org/10.1016/j.surfcoat.2014.04.051

11. MURALIDHARA, H.B., NAYAKA, Y. ARTHOBA, BALASUBRAMANYAM, J., KUMAR, K. YOGESH, HANUMANTHAPPA, H., VEENA, M.S., Electrodeposition of Zn-Graphite nanoparticles composite and their characterization, J. Chem. Pharm. Res., 4 (1), 2012, 440-449.

12.ANWAN, S., KHAN, F., ZHANG, Y., Corrosion behaviour of Zn-Ni alloy and Zn-Ni-nano-TiO 2 composite coatings electrodeposited from ammonium citrate baths, Process. Saf. Environ., 141, 2020, 366-379. https://doi.org/10.1016/j.psep.2020.05.048

13.BINDIYA, S., BASAVANNA, S., NAIK, Y.A., Electrodeposition and Corrosion Properties of Zn$\mathrm{V}_{2} \mathrm{O}_{5}$ Composite Coatings, J. Mater. Eng. Perform., 21 (9), 2012, 1879-1884.

https://doi.org/10.1007/s11665-011-0099-6

14. DHIRE, T.M., ZUHAILAWATI, H., ANASYIDA, A.S., Effect of current density on corrosion and mechanical properties of Zn-SiC composite coating, Mater. Today, 17 (3), 2019, 664-671.

https://doi.org/10.1016/j.matpr.2019.06.348

15.VASILAKOPOULOS, D., BOUROUSHIAN, M., Electrochemical codeposition of PMMA particles with zinc, Surf. Coat. Technol., 205 (1), 2010, 110-117. https://doi.org/10.1016/j.surfcoat.2010.06.011 16.HOVESTAD, A., HEESEN, R.J.C.H.L., JANSSEN, L.J.J., Electrochemical deposition of zincpolystyrene composites in the presence of surfactants, J. Appl. Electrochem., 29 (3), 1999, 331-338. https://doi.org/10.1023/A:1003477000602

17.BAI, X., TRAN, H., YU, D., VIMALANANDAN, A., HU, X., ROHWERDER, M., Novel conducting polymer based composite coatings for corrosion protection of zinc, Corros. Sci., 95, 2015, 110-116. https://doi.org/10.1016/j.corsci.2015.03.003

18.PAZDEROVA, M., BRADAC, M., VALAS, M., Qualitative analysis of composite Zn-PTFE coatings, Mm Sci. J., 11, 2010, 208-209. DOI: 10.17973/MMSJ.2010_11_201016

19.KAMBUROVA, K., BOSHKOVA, N., TABAKOVA, N., BOSHKOV, N., RADEVA, T., Application of polymeric modified polyaniline-silica particles for improved corrosion resistance of hybrid zinc coatings, Colloids Surf. A Physicochem. Eng. Asp, 592, 2020, 124546.

https://doi.org/10.1016/j.colsurfa.2020.124546

20.TUAWERI, T.J., ADIGIO, E.M., JOMBO, P.P., A Study of Process Parameters for Zinc Electrodeposition from a Sulphate Bath, Int. J. Eng. Sci. Invention Res. Dev., 2 (8), 2013, 17-24.

21.RAIESSI, R., SAATCHI, A., GOLOZAR, M.A., SZPUNAR, J.A., Effect of surface preparation on zinc electrodeposited texture, Surf. Coat. Technol., 197 (2-3), 2005, 229-237.

https://doi.org/10.1016/j.surfcoat.2004.09.024

22.ZOUARI, I., LAPICQUE, F., An electrochemical study of zinc deposition in a sulfate medium, Electrochim. Acta, 37 (3), 1992, 439-446. https://doi.org/10.1016/0013-4686(92)87033-V 
23.VASILAKOPOULOS, D., BOUROUSHIAN, M., SPYRELLIS, N., Texture and morphology of zinc electrodeposited from an acid sulfate bath, T.I. Met. Finish., 79 (3), 2001, 107-111.

https://doi.org/10.1080/00202967.2001.11871375

24.SALLES, R.C.M., de OLIVIERA, C.G., DIAZ, S.L., BARCIA, O.E., MATTOS, O.R., Electrodeposition of $\mathrm{Zn}$ in acid sulphate solutions: pH effects, Electrochim. Acta, 56 (23), 2011, 7931-7939. https://doi.org/10.1016/j.electacta.2010.12.026

25.REN, F.Z., YIN, L.T., WANG, S.S., VOLINSKY, A.A., TIAN, B.H., Cyanide-free silver electroplating process in thiosulfate bath and microstructure analysis of Ag coatings, T. Non. Ferr. Metal Soc., 23 (12), 2013, 3822-3828. https://doi.org/10.1016/S1003-6326(13)62935-0

26. DARKEN, J., Recent Progress in Bright Plating from Zincate Electrolytes, Trans. IMF, 57 (1), 1979, 145-151. https://doi.org/10.1080/00202967.1979.11870505

27. ZHANG, Q.B., HUA, Y.X., DONG, T.G., ZHOU, D.G., Effects of temperature and current density on zinc electrodeposition from acidic sulfate electrolyte with [BMIM] $\mathrm{HSO}_{4}$ as additive, J. Appl. Electrochem., 39, 2009, 1207. https://doi.org/10.1007/s10800-009-9786-5

28. ZHANG, Q.B., HUA, Y.X Effects of [HMIM] $\mathrm{HSO}_{4}$ and $[\mathrm{OMIM}] \mathrm{HSO}_{4}$ on the electrodeposition of zinc from sulfate electrolytes, J. Appl. Electrochem., 39, 2009, 1185.

https://doi.org/10.1007/s10800-009-9783-8

29.SAJJADNEJAD, M., MOZAFARI, A., OMIDVAR, H., JAVANBAKHT, M., Preparation and corrosion resistance of pulse electrodeposited $\mathrm{Zn}$ and $\mathrm{Zn}-\mathrm{SiC}$ nanocomposite coatings, Appl. Surf. Sci., 300, 2014, 1-7. https://doi.org/10.1016/j.apsusc.2013.12.143

30.SNOWDON, R.C., Electrolytic Precipitation of Zinc, J. Phys. Chem., 11 (5), 1907, 369-381. https://doi.org/10.1021/j150086a003

31.LOTO, C.A., Electrodeposition of Zinc from Acid Based Solutions: A Review and Experimental Study, Asian J. Appl. Sci., 5 (6), 2012, 314-326. DOI: 10.3923/ajaps.2012.314.326

32.SOROUR, N., ZHANG, W., GHALI, E., HOULACHI, G., A review of organic additives in zinc electrodeposition process (performance and evaluation), Hydrometallurgy, 171, 2017, 320-332.

https://doi.org/10.1016/j.hydromet.2017.06.004

33.KAVITHA, B., SANTHOSH, P., RENUKADEVI, M., KALPANA, A., SHAKKTHIVEL, P., VASUDEVAN, T., Role of organic additives on zinc plating, Surf. Coat. Technol., 201 (6), 2006, 34383442. https://doi.org/10.1016/j.surfcoat.2006.07.235

34.NAYANA, K.O., VENKATESHA, T.V., Synergistic effects of additives on morphology, texture and discharge mechanism of zinc during electrodeposition, J. Electroanal. Chem., 663 (2), 2011, 98-107. https://doi.org/10.1016/j.jelechem.2011.10.001

Manuscript received: 26.07 .2021 